\title{
Rural and Suburban Population Surge Following Detonation of an Improvised Nuclear Device: A New Model to Estimate Impact
}

Michael Meit, MA, MPH; Irwin Redlener, MD; Thomas W. Briggs, MPS; Mike Kwanisai, PhD; Derrin Culp, MIA, MCRP; David M. Abramson, PhD, MPH

\section{ABSTRACT}

Background: The objective of the study was to model urban evacuation into surrounding communities after the detonation of an improvised nuclear device (IND) to assist rural and suburban planners in understanding and effectively planning to address the effects of population surges.

Methods: Researchers developed parameters for how far evacuees would travel to escape disasters and factors that would influence choice of destination from studies of historical evacuations, surveys of citizens' evacuation intentions in hypothetical disasters, and semistructured interviews with key informants and emergency preparedness experts. Those parameters became the inputs to a "push-pull" model of how many people would flee in the 4 scenarios and where they would go.

Results: The expanded model predicted significant population movements from the New York City borough of Manhattan and counties within $20 \mathrm{~km}$ of Manhattan to counties within a 150-mi radius of the assumed IND detonation. It also predicted that even in some communities located far from Manhattan, arriving evacuees would increase the population needing services by $50 \%$ to $150 \%$.

Conclusions: The results suggest that suburban and rural communities could be overwhelmed by evacuees from their center city following an IND detonation. They also highlight the urgency of educating and communicating with the public about radiation hazards to mitigate panic and hysteria, anticipating the ways in which a mass exodus may disrupt or even cripple rescue and response efforts, and devising creative ways to exercise and drill for an event about which there is great denial and fatalism.

(Disaster Med Public Health Preparedness. 2011;5:S143-S150)

Key Words: improvised nuclear device, evacuation model, push-pull model, rural preparedness

$\mathrm{S}$ ince the terrorism events of September 11, 2001, political leaders, academics, and government agencies consistently and with increasing urgency have warned Americans about the risks of nuclear terrorism on US soil. During the last decade, Congress, the Department of Homeland Security, and the Department of Commerce have directed large appropriations to screening of cargo and citizens at foreign and domestic ports and at US border crossings to prevent fissile material-the essential raw material of an improvised nuclear device (IND)-from entering the United States. The Department of Homeland Security also has invested substantial sums promoting next-generation nuclear detection technology and enhancing local government capacity to respond to catastrophic events. It has devised and drilled 15 "national planning scenarios" that are included in the National Preparedness Guidelines, including 1 planning scenario built around the detonation of a 10-kiloton (kT) IND.

Through the Cooperative Threat Reduction Program, commonly known as Nunn-Lugar, the United States has directed billions of dollars to Russia and other coun- tries of the former Soviet Union to identify, deactivate, dispose of, and secure the Cold War's nuclear arsenal and provide employment to nuclear scientists and technicians previously employed in the Soviet military and arms industries. Federal agencies and the state and local counterparts that rely upon federal funding have embraced a broad culture of all-hazards preparedness. Even without considering the presumed substantial intelligence and law enforcement assets that the US government uses to detect illicit commerce in nuclear materials, the US government's multilayered defenses against domestic nuclear terrorism suggest that our government continues to view the threat as palpable and serious.

It is only recently that a critical mass of analysts has begun to address seriously what may happen if prevention failed and a terrorist succeeded in detonating even a low-yield $(10 \mathrm{kT})$ IND in the downtown or port area of a major American city. (For an introduction to this topic, see National Center for Disaster Preparedness: Day Three: Regional Resiliency and Health Challenges in the Aftermath of Nuclear Terrorism, at http://www 
.gis09.com/FINALDay3Sum060110.pdf. This paper discusses the development of a tool to model 1 limited aspect of such a horrific scenario- the potentially chaotic evacuation of tens or hundreds of thousands, perhaps millions, of people after the detonation.)

The detonation of even a small IND in a major American city would cause massive mortality and morbidity and a collapse of infrastructure. Also, it is widely believed that an IND attack would create a difficult-to-control spontaneous mass evacuation. Such an exodus would have significant adverse effects on the communities that would receive a massive population surge in a short time. A mass evacuation into or through a community would compromise existing resources and infrastructure, creating concern about food supplies, water, gasoline, shelter and sanitation, health systems, transportation, and law enforcement. Meeting the enormous scale of arriving evacuees' needs while simultaneously preserving services to residents would be a logistical challenge requiring coordination at multiple levels.

A mass evacuation also could congeal highways, secondary roads, and local streets spreading outward from the regional center. Such gridlock would compromise plans to mobilize first responders and transportation resources, move victims to treatment facilities, deploy local law enforcement, establish mobile hospitals, and distribute state and federal relief and response supplies to where they are needed. Estimating the evacuationdriven population surge after an IND detonation is critical to effective advance planning to address these challenges.

\section{METHODS}

\section{The National Opinion Research Center (NORC) at the University of Chicago Evacuation Modeling Project}

Modeling the evacuation of urban areas has focused in general on ensuring the efficient transfer of the largest possible number of city residents beyond the danger zone. Despite mass urban evacuation events such as Hurricanes Katrina, Rita, and Wilma, efforts to assess where evacuees actually went or are likely to go and the impact evacuees had or potentially may have on destination communities have been limited. The original purpose of this project was to provide a resource for rural and suburban emergency planners to conceptualize the potential effects of an urban evacuation on their communities. It was inspired in part by evidence, subsequently reinforced by NORC key informant interviews described in this section, that most rural and suburban planners had not considered the effects of population surge after urban disasters and that lack of understanding of this phenomenon was a barrier to planning. NORC extended the project in 2010 to develop a model for predicting the numbers of evacuees that suburban and rural communities may receive after the detonation of an IND in midtown Manhattan (New York City).

The model developed through this project provides estimates of numbers of evacuees and their distributions based upon a conceptual "push-pull" model such as has been used in analyses of human migration..$^{1-3}$ In this model, the degree of the "push" is dependent upon the nature of the precipitating event and the "pull" reflects the relative attractiveness of surrounding communities as potential evacuee destinations. In light of the limited public health infrastructures and sparse community resources in many rural and even suburban areas, estimating population surge after urban disasters is a critical first step to effective emergency planning.

\section{Variable Identification}

We began by identifying variables believed to be predictive of urban-to-rural evacuation. Our preferred sources were variables and data culled from the reporting on actual disaster events such as hurricanes and the 1979 Three Mile Island (TMI) nuclear reactor accident. Because such data are limited, we also used studies of intended evacuation behavior, including a 2007 national survey of urban citizens' evacuation intentions, conducted by the authors. ${ }^{4}$ We supplemented the available literature with interviews with preparedness experts at the national level and in rural and urban communities and vetted all of our data with an expert advisory committee to select and weight a set of predictive variables. Using the variables identified from these sources, we developed a model to predict population movements within an urban region. Based upon this model, we developed an online geographic information system tool that modeled evacuation in the 3 scenarios for the 100 largest metropolitan areas in the United States and for all of the state capitals (www.cei.psu.edu/evac). In 2010, we modified the tool to model evacuation after the detonation of an IND in midtown Manhattan (www.cei.psu.edu/evac/nyc.html).

Historical data and research evidence came from several sources. A number of studies were conducted in the years after the TMI nuclear power plant incident. The hurricane-prone conditions of the southeastern United States also have led to significant research and publication on hurricanes and other natural disasters that can result in evacuation. More recently, the threat of terrorism after the attacks on September 11, 2001, has prompted an emergence of research on issues related to hypothetical acts of terror and the need for preparedness and evacuation planning.

Johnson and Ziegler argue that perceived risk is greater in a radiological emergency than other types of disasters ${ }^{5}$ and note that evacuees flee farther from a radiological disaster than other events. ${ }^{6}$ They noted that for the TMI incident, the observed 85-mi median evacuation distance of central Pennsylvania residents was farther than evacuees traveled when fleeing from any of the more than 500 natural and technological disasters in the United States between 1960 and 1973, as cataloged by the Environmental Protection Agency. ${ }^{7}$ Although the Mississauga, Canada, train derailment in 1979 prompted the evacuation of approximately 250000 people, those evacuees generally remained within the Toronto-Hamilton corridor, only a few miles from the spreading chlorine gas cloud. ${ }^{6}$ Similarly, Ziegler and Johnson note that during natural disasters such as floods, evacu- 
ees tend to travel no farther than the projected high water line. ${ }^{6}$ At the time of their writing, the longest median evacuation distance on record in response to a Gulf Coast hurricane had been only $80 \mathrm{mi}$. Various studies cited by Ziegler and Johnson found the median evacuation distances in response to TMI to be 85, 100, and 112 mi. $^{6-9}$ More recently, Dow and Cutter observed that in the context of hurricanes involving South Carolina, the percentage of evacuees traveling out of state (and, by implication, the distance traveled during evacuations) has increased, with $15 \%$ of evacuees traveling beyond the state border during Hurricane Bertha in July 1996, 28\% during Hurricane Fran in September 1996, and 38\% during Hurricane Floyd in September $1999 .{ }^{10}$ The 3 reasons given by evacuees for longerdistance travel were friends and family offering shelter lived farther away, the danger from the storm was great, and it was necessary to travel that far to find available lodging. ${ }^{11}$

As part of this project, NORC at the University of Chicago conducted a survey in 2007 of respondents' intentions to evacuate after the detonation of a dirty bomb or during an influenza pandemic under varying conditions of external influence, as well as likely evacuation distance and known destinations. Prior evacuation surveys were used as a basis for survey content development, combined with qualitative research conducted as part of the NORC study; studies protocols were approved by the NORC at the University of Chicago institutional review board. Survey respondents were a nationally representative sample of 1505 adults living in urban and suburban areas. Respondents were reached by telephone in March 2007 and administered a 15-item survey questionnaire as part of the EXCEL National Telephone Omnibus Study, conducted by International Communications Research (Media, PA). (EXCEL uses a fully replicated, stratified, single-stage random-digit-dialing sample of telephone households. The EXCEL Omnibus Survey is conducted on a weekly basis, allowing survey questions to be added on a rolling basis. Nonresponses [after 2 attempted calls] are replaced with matched respondents based on standard demographic information until the desired sample size is achieved, providing the relative advantage of quick survey turnaround. Details on response rate are not provided because this matched respondent process is used in lieu of continued followup. Using this method, full survey completion was achieved in a 2-week process.) International Communications Research also collected standard demographic and classification data for each respondent household. Although $77 \%$ and $91 \%$ of respondents intended to evacuate if the government suggested or ordered evacuation, for the pandemic influenza and dirty bomb scenarios, respectively, $27 \%$ and $40 \%$ responded that they would still intend to evacuate even if it was against government advice. In both scenarios, $55 \%$ of respondents indicated that they would be likely to travel to a rural destination and $52 \%$ of respondents indicated that they would likely remain within a 150 -mi radius. ${ }^{4}$

Certain characteristics may draw evacuees to particular communities. Analyses of actual evacuations, surveys of respondents' in- tended evacuation behavior, and projections of evacuations in hypothetical disaster scenarios suggest that sheltering with family or friends is the overwhelming first choice of evacuees, followed by hotels and motels, with public emergency shelters a destination of last resort. An analysis of a hypothetical nuclear power plant accident in which no evacuation order was given estimated that $60 \%$ of evacuees would seek shelter with family or friends, ${ }^{6}$ whereas following TMI, between $74 \%$ and $81 \%$ of the actual evacuees traveled to the homes of family and friends. ${ }^{7}$ The 1984 hypothetical study also estimated that $19 \%$ of evacuees would seek shelter in hotels and motels, whereas only $6 \%$ would seek safety in public shelters. A survey of evacuation destinations after Hurricane Bonnie showed that approximately $70 \%$ of evacuees stayed with friends or family, $16 \%$ stayed in a hotel or motel, and $5 \%$ stayed in a public shelter ( $9 \%$ responded "other"). As with the hypothetical nuclear incident studies, a survey of intentions concerning evacuation from a hypothetical hurricane produced slightly lower percentages, with $60 \%$ reporting that they would stay with friends and family, $24 \%$ in a hotel or motel, $12 \%$ in a shelter, and $4 \%$ doing something else. ${ }^{12}$

As the final step in identifying push-pull factors, NORC conducted interviews with 17 key informants representing academia, government, and the private sector. To incorporate representation from varied geographic regions and city sizes, key informants were selected from 6 paired rural and urban communities (rural informants were located within 20 minutes to 4 hours of the urban informant locale) and 5 national preparedness experts were chosen. The semistructured interviews focused on issues related to likely evacuee behavior in various scenarios and on critical features of surrounding communities that would make them more or less attractive as destination sites. ${ }^{4}$ Based upon the reviewed literature and the concurrence of key informants, we selected the following "push" and "pull" factors in developing our model algorithms:

- Push: People will evacuate farther from a radiological event than from a natural hazard such as a hurricane, and as more people evacuate, the distance traveled becomes greater. As such, key push variables are the number of people evacuating and the distance traveled. As a result, the destination county's distance from the IND detonation becomes a key factor in developing the algorithm.

- Pull: Pull variables influence the relative attractiveness of potential destination communities and include items such as the presence of friends and family, the number and availability of hotel rooms, the capacity and quality of the road networks providing access to the destination, the number of hospital beds and pharmacies, and the extent of second/vacation homeownership. In developing the algorithm we limited pull variables to those that were available in national data sets containing information at the county level (Table 1).

\section{Algorithm Development}

To predict spontaneous urban evacuation and the subsequent distribution of the evacuating population, we developed a con- 


\section{TABLE 1}

\begin{tabular}{|ll}
\hline Variables and Data Sources & \\
Variable & \multicolumn{1}{c}{ Source } \\
Distance and road network information & \\
$\quad$ Primary highways with limited access & Smith Travel Research \\
Primary highways without limited access & Smith Travel Research \\
Friends and family (nativity) & 2000 US Census \\
Vacant housing units: for seasonal, & 2000 US Census \\
$\quad$ recreational, or occasional use & \\
$\begin{array}{l}\text { Hotel/motel rooms } \\
\text { Recreational vehicle parks and recreational }\end{array}$ & Smith Travel Research \\
$\quad$ camps & \\
$\begin{array}{l}\text { Health and medical resources } \\
\text { Hospital beds }\end{array}$ & \\
$\begin{array}{l}\text { Pharmacies } \\
\text { Population information } \\
\text { Living in same House in 1995 and } \\
2000 \text { ( }>5 \text { y old) }\end{array}$ & Bureau of Labor Statistics \\
Household moved into unit 1990-1994 & 2000 US Census \\
Household moved into unit 1970-1979 & 2000 US Census \\
Household moved into unit 1969 or before & 2000 US Census \\
Population density & 2000 US Census
\end{tabular}

ceptual push-pull mathematical model using weighted combinations of key assumptions based upon information culled from evacuation literature, the NORC survey, and expert opinion. The push-pull model assumes that a pushing force is uniquely generated by each scenario at the urban origin, and a pulling force or attractiveness is generated by features of the potential destination communities. Using the previously described analysis, we set a percentage of the urban population expected to evacuate upon a disaster. We subsequently distributed those evacuees using each destination's relative pulling force across all counties located within a 150 -mi radius of the affected urban center. Because the number of counties rises proportionally as the radius of the potential evacuation zone increases, we limited the radius to $150 \mathrm{mi}$ to prevent findings from becoming too diffuse. Using the 2007 NORC survey findings, we set the proportion of evacuees remaining within the 150 -mi radius at $52 \%{ }^{4}$ ( $25 \%$ within $50 \mathrm{mi} ; 27 \%$ between 50 to $150 \mathrm{mi}$ ). The model does not address the destinations of evacuees assumed to travel beyond the $150-\mathrm{mi}$ radius.

The model distributes evacuees that remain within the 150-mi radius of the affected area across the destination counties based upon the counties' relative pull scores. A pull score is a standardized measure designed to reflect the potential destination's relative attractiveness to evacuees. Computing each county's pull score was accomplished in 5 steps. First, we transformed the data for each pull variable (eg, the number of hotel rooms in a county) into standardized scores so that all of the variables, regardless of their unit of measurement, could be compared. Second, using research findings and concurrence of an expert panel comprising regional public health and emergency management personnel and academic modelers and preparedness researchers, we weighted each variable to reflect its relative contribution to the destination's attractiveness to evacuees. Third, we generated weighted standardized scores, providing a single total score for each county in each scenario. In the fourth step we obtained ratios of weighted standardized scores for all of the counties. These ratios measure, under similar conditions and irrespective of distance from the source, the probability that an evacuee would choose a county as its final destination. This, however, does not consider the distance from the event and its effect on the final destination. The fifth and final step was a computation of each county's relative score by considering its relative attractiveness and distance from the event. The fifth step estimated the probabilities of evacuees from the affected area traveling to different destinations at varying distances. The distribution of evacuees is then estimated by calculating expected total evacuees by probabilities of reaching each of the different destinations within the 150-mi radius.

In February 2010, in conjunction with the National Center for Disaster Preparedness' February 2010 Day Three: Regional Resiliency and Health Challenges in the Aftermath of Nuclear Terrorism roundtable, we extended our model to include evacuation after the detonation of a 10-kT IND in midtown Manhattan. To accommodate this scenario, we modified the push side of the model. We decreased the percentage of the population evacuating Manhattan from $65 \%$ to $40 \%$ to reflect a much greater level of injuries and fatalities from an IND detonation compared with other urban disasters, while increasing the overall Manhattan population to include an estimated 1.48 million commuters and 910000 tourists. (NORC estimated the average daily commuter population based upon data from the 2000 US Census [http://www.census.gov/population/www/socdemo /journey.html] and average daily tourist population based upon data from the New York City Office of Tourism [http://www .nycgo.com/?event=view.article\&id=78912; estimate based on annual number of tourists and 7-day average length of stay].) In addition, we assumed that a large number of residents would evacuate the counties immediately surrounding the borough of Manhattan (ie, those within a 20-km radius) and Manhattan itself. After adjusting these county populations for the commuters whom we were counting in the adjusted Manhattan population, we assumed that $80 \%$ would evacuate from counties within $10 \mathrm{~km}$ of Manhattan and $60 \%$ from counties between 10 and $20 \mathrm{~km}$.

Based upon the long evacuation distances observed during the TMI accident and upon expert opinion, we further modified the IND scenario to reflect that evacuees may travel farther and set the proportion of evacuees remaining within the 150 -mi radius at $40 \%$ (13\% within $50 \mathrm{mi}, 27 \%$ between 50 and $150 \mathrm{mi})$ compared with $52 \%$ in the original model. (Although the model does not incorporate the transportation modalities used in evacuating, the authors are inclined to believe that upon an IND detonation, most public transportation and air travel would be severely disrupted or constrained, and most evacuees would travel by means of personal transportation.) The only additional modification made to the IND scenario was to reduce the relative 
pull of Long Island by 50\%, to reflect the lower likelihood of evacuees traveling to a destination with more limited accessibility.

In the context of considering likely evacuation behavior, it is worth noting that there has been much reporting recently on an emerging consensus among federal agencies and major city public health departments that sheltering in place would be the most effective way to prevent harmful radiation exposure and contamination, and on incipient governmental efforts to communicate this message. ${ }^{13,14}$ In fact, the most comprehensive federal government statement on this matter, the Planning Guidance for Response to a Nuclear Detonation, ${ }^{15}$ states unequivocally that "the best initial action immediately following a nuclear explosion is to take shelter in the nearest and most protective building or structure and listen for instructions from authorities," and that "no evacuation should be attempted until basic information is available regarding fallout distribution and radiation dose rates." Given the well-documented fear of radiation among both first responders and the public at large, and leaders' reluctance to emphasize this issue, it likely will be many years before studies may document a change in citizens' evacuation behavior or intentions that is sufficient to justify reconsidering the overall assumption of evacuation intent inherent to the model.

\section{RESULTS}

The IND version of the model generates estimates of the population surge from arriving evacuees for counties within a 150-mi radius of Manhattan. Outputs demonstrate significant population movement after urban disasters. Figure 1 shows the number of evacuees projected to be received in each destination county within the 150-mi radius, and Figure 2 shows the projected percentage increase in the destination county's population. Although larger numbers of evacuees will travel to other urban areas because of a greater likelihood of family relationships and greater resource availability (Figure 1), smaller communities tend to receive larger proportions of evacuees relative to their population (Figure 2). Table 2 presents outputs for a sample of destination counties, highlighting total postevacuation population and percentage population change for the IND scenario.

\section{COMIMENT}

The approach described in this article represents an initial attempt to develop a predictive model to determine the number of evacuees likely to seek shelter in rural and suburban counties after a disaster or public health emergency in a nearby urban center. Prior work has focused on how to move the maximum number of urban residents away from potential danger; however, there has been little focus on determining the im-

\section{FIGURE 1}

\section{Predicted number of evacuees in destination counties}

Urban to Rural Evacuation Tool Expected target counties for evacuees from New York City, NY from Scenario: 3 day out

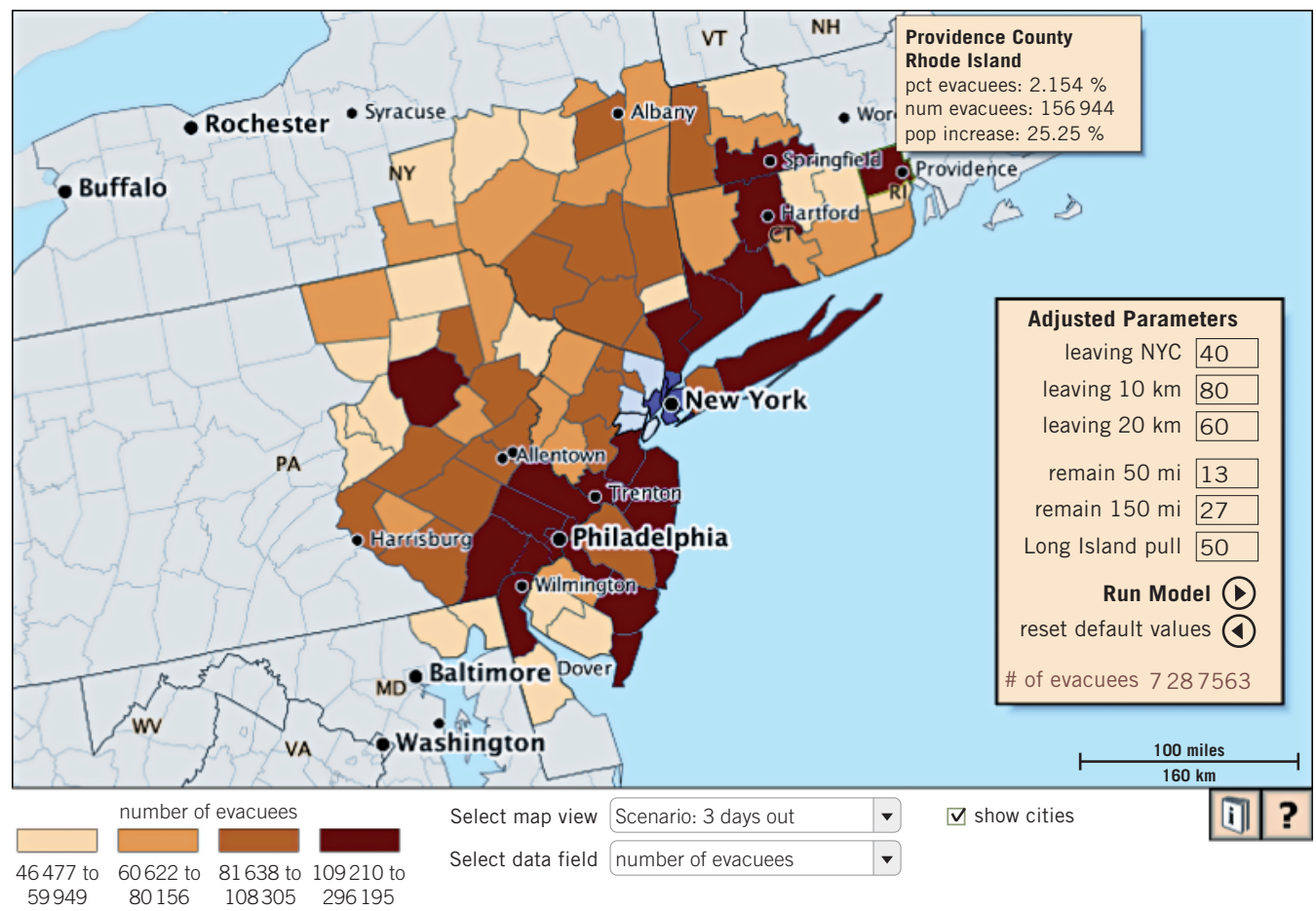


pact that such an evacuation may have on the destination communities.

A key finding, based upon our model, is that rural counties will experience the greatest impact of population increase relative to resident population. Although urban counties are likely to receive greater numbers of evacuees, their ability to absorb and care for these individuals is also greater. The greater "relative impact" of evacuees on rural communities has significant implications for sheltering, feeding, and providing medical care to those evacuees. Given the limited public health, health care delivery, water and sanitation, and administrative infrastructures of rural communities, these systems may be quickly overwhelmed in the event of a mass urban evacuation.

Such a mass evacuation is likely to include a significant number of people with trauma and burn injuries and with radiation exposure and contamination. The ability of the receiving communities to treat these evacuees adequately is questionable. Recent studies of urban health care systems have reported a broad

\section{FIGURE 2}

\section{Percentage of change in destination county population}

Urban to Rural Evacuation Tool Expected target counties for evacuees from New York City, NY from Scenario: 3 day out

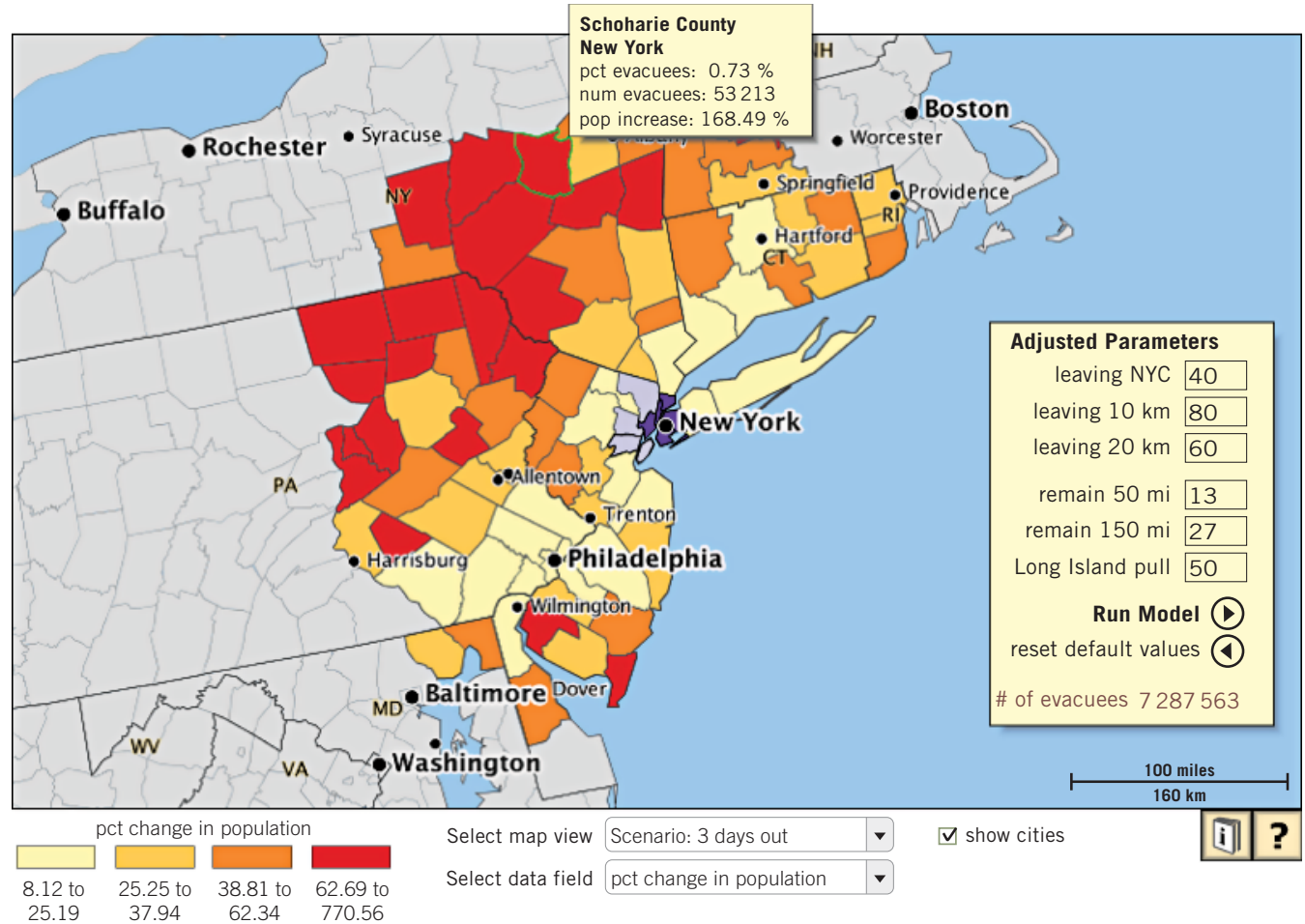

\section{TABLE 2}

\begin{tabular}{|c|c|c|c|c|c|c|}
\hline County & State & $\begin{array}{l}\text { Distance from } \\
\text { Manhattan } \\
\text { (in Miles) }\end{array}$ & $\begin{array}{c}\text { Original } \\
\text { Population }\end{array}$ & $\begin{array}{l}\text { Evacuees } \\
\text { Received }\end{array}$ & $\begin{array}{c}\text { Total } \\
\text { Post-Evacuation } \\
\text { Population }\end{array}$ & $\begin{array}{c}\text { Percent } \\
\text { Population } \\
\text { Change }\end{array}$ \\
\hline Hartford & CT & 97 & 857183 & 167182 & 1024365 & 19.5 \\
\hline Windham & CT & 127 & 109091 & 50518 & 159609 & 46.31 \\
\hline Cape May & NJ & 120 & 102326 & 121424 & 223750 & 118.66 \\
\hline Middlesex & $\mathrm{NJ}$ & 32 & 750162 & 116098 & 866260 & 15.48 \\
\hline Delaware & NY & 112 & 48055 & 70411 & 118466 & 146.52 \\
\hline Nassau & NY & 20 & 1334544 & 108305 & 1442849 & 8.12 \\
\hline Rockland & NY & 27 & 286753 & 83424 & 370177 & 29.09 \\
\hline Philadelphia & PA & 80 & 1517550 & 296195 & 1813745 & 19.52 \\
\hline Susquehanna & PA & 119 & 42238 & 50294 & 92532 & 119.07 \\
\hline
\end{tabular}


consensus that in many US cities, the detonation of a 10- to 20-kT IND could destroy a large portion of the health care infrastructure, including many of the facilities capable of providing treatment for severe burn injuries and mass radiation exposure $^{16,17}$; that most hospitals view themselves as unprepared to respond to a nuclear event ${ }^{18}$; and that similar deficiencies exist with regard to first response and prehospital care, triage and altered standards of care, medical countermeasures stockpiles, health workforce absenteeism, and regional coordination for extreme events. ${ }^{19}$ There was a clear consensus among participants in the Day 3 Roundtable that "no American city or region, even with abundant state and federal government and military support, has sufficient health care infrastructure and resources to handle the anticipated injuries and illness from the detonation of a 10-kiloton nuclear device."20

Although our methodology is intended to provide information on numbers of likely evacuees, we caution that the purpose of presenting such estimates is to provide a resource for rural and suburban emergency planners to conceptualize the potential effects of an urban evacuation on their communities. Our intent is to stimulate rural and suburban preparedness planning among community leaders that have not previously considered the issue of secondary impact on surrounding communities. The estimates of evacuee numbers can provide an initial framework for the development of plans to respond to the potential influx of evacuees.

Our methodology has several limitations. Both the selection of predictive variables and the weighting of the variables were limited by 5 factors. First, there is sparse historical evidence from which to select variables known to predict evacuation behavior. In the United States, the only major radiological emergency occurred more than 25 years ago (TMI). More recent evacuations for which data are available tend to be hurricane or other natural disaster scenarios. We hesitate to generalize certain aspects of natural disaster evacuation research to other potential evacuation scenarios because there are confounding factors in natural disasters, such as damage to property and prior natural disaster experience for some individuals. In addition, natural disasters frequently have a larger radius of impact or, in the case of a hurricane, an expected path that may affect individuals' choice of evacuation route and destination. As a result, we have attempted wherever possible to confirm the reliability of predictive variables across different types of disaster scenarios. A second factor is the use of survey research to identify and weight variables. In general, disaster and evacuation surveys use either a prospective or retrospective design, and a known disconnect exists between respondents' stated intentions and their actual behavior. Although a handful of surveys compare stated intentions with actual behavior in a subsequent disaster, the unpredictable nature of disasters make such research difficult. A third limiting factor is the use of a limited number of key informants and advisors to identify variables where gaps exist in the literature. Attempting to mitigate this factor, we included a wide sample of informants and advisors at vari- ous levels and in various positions related to emergency preparedness. The fourth limiting factor was the restriction of variables to those for which we could access national data sets with information at the county level. Although more granular data sources may exist for other plausible pull factors such as actual hospital and intensive care unit bed vacancies, actual pharmaceutical and ventilator inventories, and actual hotel vacancy rates, these were not available in forms that could be incorporated uniformly across jurisdictions. Finally, because we focused primarily on creating a framework to help planners conceptualize localized effects of an evacuation from a nearby urban center, we opted for assumptions that are strongly supported by a comprehensive literature review and contemporary expert opinion, rather than for totally unassailable assumptions. We hope that future modeling refinements will enable local planners to incorporate alternative assumptions to perform sensitivity analyses and formulate their own conclusions about their vulnerability.

\section{CONCLUSIONS}

The NORC Evacuation Modeling Project strongly supports the conclusion voiced by experts at the National Center for Disaster Preparedness Day Three roundtable- - that a spontaneous mass evacuation from an IND blast in an urban center could lead to a dramatic population surge in surrounding communities. Such an exodus would extend panic and devastation far beyond the locus of the event, draining food, water, medicines, gasoline, and other resources from surrounding communities and potentially causing gridlock that would severely compromise many elements of the official disaster response. The model's projected population increases of up to $150 \%$ in surrounding communities add urgency to the Day 3 recommendations for enhanced public education and official communications to reduce spontaneous evacuation and for mass evacuation drills and exercises. Such efforts would help to mitigate concerns described above, and by increasing sheltering in place and reducing citizens' exposure to radiation, they also could increase survivability. These and other equally sobering issues highlight the urgent need for both a next generation of evacuation simulations and federally mandated and funded regional IND response planning and preparation.

Author Affiliations: Mr Meit, Mr Briggs, and Dr Kwanisai are with the National Opinion Research Center at the University of Chicago; Dr Redlener, Mr Culp, and Dr Abramson are with the Columbia University Mailman School of Public Health.

Correspondence: Address correspondence and reprint requests to Michael Meit, Public Health Research Department, NORC at the University of Chicago, 4350 East West Hwy, Suite 800, Bethesda, MD 20814 (meit-michael@norc.org).

Received for publication September 27, 2010; accepted January 10, 2011.

Funding for this study was provided by the Western New York Public Health Alliance Advanced Practice Center, the Health Resources and Services Administration Office of Rural Health Policy, and the Centers for Disease Control and Prevention.

Author Disclosures: The authors report no conflicts of interest. 
Acknowledgments: The authors thank the Western New York Public Health Alliance Advanced Practice Center and the National Association of County and City Health Officials for supporting the development of the evacuation modeling tool. The authors also thank Karen Levin, RN, MPH, National Center for Disaster Preparedness, for coordinating the Day Three Roundtable that inspired this analysis, and for reviewing the manuscript and providing insights from the perspective of public health practice.

\section{REFERENCES}

1. Ravenstein E. The laws of migration. J Stat Soc Lond. 1885;48:167-235.

2. Dorigo G, Tobler W. Push-pull migration laws. Ann Assoc Am Geogr. 1983; 73:1-17.

3. Tobler W. Migration: Ravenstein, Thorntwaite, and beyond. Urban Geogr. 1995;16:327-343.

4. Meit M, Briggs T, Kennedy A. Urban to rural evacuation: planning for rural population surge. Final report prepared for the Health Resources and Services Administration, Office of Rural Health Policy. NORC at the University of Chicago. http://www.norc.org/NR/rdonlyres/D0577161-5CFF -4F4A-A243-2BB67826A256/0/URBANTORURALEVACUATION PLANNINGFORRURALPOPULATIONSURGE_FinalReport.pdf. Accessed January 27, 2011.

5. Johnson JH, Zeigler DJ. Distinguishing human responses to radiological emergencies. Econ Geogr. 1983;59:386-402.

6. Zeigler DJ, Johnson JH. Evacuation behavior in response to nuclear power plant accidents. Prof Geogr. 1984;32:207-215.

7. Ziegler DJ, Brunn SD, Johnson JH. Evacuation from a nuclear technological disaster. Geogr Rev. 1981;71:1-16.

8. Flynn CB. Three Mile Island Telephone Survey: Preliminary Report on Procedures and Findings. NUREG/CR-1093. Tempe, AZ: Mountain West Research; 1979

9. Barnes K, Brosius J, Cutter S, Mitchell JK. Response of Impacted Population to the Three Mile Island Nuclear Reactor Accident: An Initial Assessment. Discussion Paper no. 13. New Brunswick, NJ: Rutgers University; 1979.

10. Dow K, Cutter SL. Emerging hurricane evacuation issues: hurricane Floyd and South Carolina. Nat Hazards Rev. 2002;3:12-18.

11. US Army Corps of Engineers and Federal Emergency Management Agency.
Hurricane Floyd Assessment. Tallahassee, FL: Post, Buckley, Schuh \& Jernigan; 2000.

12. Whitehead JC, Edwards B, Van Willigen M, Maiolo JR, Wilson K, Smith KT. Heading for higher ground: factors affecting real and hypothetical hurricane evacuation behavior. Global Environ Change B: Environ Hazards. 2000;2:133-142.

13. Broad WJUS. rethinks strategy for the unthinkable. NY Times. December 16, 2010:A1. http://www.nytimes.com/2010/12/16/science/16terror .html. Accessed January 27, 2011.

14. Sternberg SLA. dry run shows urban nuke attack "a survivable event." USA Today. December 16, 2010. http://www.usatoday.com/news/nation/2010 -12-15-nuclear-fallout-test_N.htm. Accessed January 27, 2011.

15. Executive Office of the President, Interagency Policy Coordination Subcommittee for Preparedness and Response to Radiological and Nuclear Threats. Planning Guidance for Response to a Nuclear Detonation, Second Edition. http://hps.org/hsc/documents/Planning_Guidance_for _Response_to_a_Nuclear_Detonation-2nd_Edition_FINAL.pdf. Published June 2010. Accessed January 27, 2011.

16. Bell WC, Dallas CE. Vulnerability of populations and the urban health care systems to nuclear weapon attack--examples from four American cities. Int J Health Geogr. 2007;6:5-33.

17. Helfand I, Forrow L, Tiwari J. Nuclear terrorism. BMJ. 2002;324(7333): 356-359.

18. Treat KN, Williams JM, Furbee PM, Manley WG, Russell FK, Stamper CD Jr. Hospital preparedness for weapons of mass destruction incidents: an initial assessment. Ann Emerg Med. 2001;38(5):562-565.

19. Redlener I, Garrett AL, Levin KL, Mener A. Regional health and public health preparedness for nuclear terrorism: optimizing survival in a low probability/high consequence disaster. http://www.ncdp.mailman.columbia .edu/files/Nuclear\%20Event-Whitepaper.pdf. Published 2010. Accessed January 27, 2011.

20. National Center for Disaster Preparedness. Day three: regional resiliency and health challenges in the aftermath of nuclear terrorism. http://www .gis09.com/FINALDay3Sum060110.pdf. Published April 2010. Accessed January 27, 2011. 